\title{
Evil geniuses: inferences derived from evidence and preferences
}

\author{
Michael C. Mensink • David N. Rapp
}

Published online: 22 March 2011

(C) Psychonomic Society, Inc. 2011

\begin{abstract}
Readers rely on descriptions of characters to generate expectations for future story events. However, readers also have preferences for how they want those events to unfold. Often, what texts imply about how characters will behave and what readers want characters to do converge on similar story events and narrative descriptions. But what are the processing consequences when expectations and preferences suggest competing possibilities? In three experiments, we explored this question utilizing short narrative texts. Each text included information designed to establish positive, negative, or neutral preferences toward characters, as well as behavioral descriptions that supported particular positive or negative character traits. In Experiments 1 and 2, when the valences of reader preferences and implied traits matched, participants overwhelmingly judged characters as likely to possess those traits. With mismatches, though, those judged likelihoods decreased in systematic ways. In Experiment 3, we observed that matches between preferences and implied traits also influenced reading times for story outcomes. These results outline how the inferences that guide narrative comprehension are influenced both by the descriptions that authors provide about characters and events, as well as by the emerging desires that readers develop for those characters and events.
\end{abstract}

Keywords Reading $\cdot$ Text processing $\cdot$ Narrative comprehension $\cdot$ Decision making $\cdot$ Language

\footnotetext{
M. C. Mensink ( $\square)$

Department of Educational Psychology, University of Minnesota, 56 East River Road,

Minneapolis, MN 55455, USA

e-mail: mens0058@umn.edu

D. N. Rapp

School of Education and Social Policy

\& Department of Psychology, Northwestern University,

2120 Campus Drive,

Evanston, IL 60208, USA
}

Fictional narratives often describe the valiant exploits of courageous protagonists as they attempt to stop the villainy of evil ne'er-do-wells. These characters can exhibit traits and engage in behaviors that encourage easy encoding of their roles as heroes and villains. For example, heroes tend to display endearing, likable qualities in the service of wellintentioned goals, while villains show detestable characteristics as they concoct sinister plans. Readers' inferences about how characters will behave and how plots will unfold are strongly influenced by these narrative consistencies, as they provide the schematic foundations for building expectations about story events (e.g., Brewer \& Lichtenstein, 1982; Jose \& Brewer, 1984; Mandler, 1984; Rapp, Gerrig \& Prentice, 2001). In addition, readers often root for the success of good characters and the failure of their evil nemeses; these wishes and desires further influence the expectations that readers build for narrative plot (Jacovina \& Gerrig, 2010; Rapp \& Gerrig, 2002, 2006).

In many narratives, however, characters display traits that blur the lines between heroes and villains, which calls into question exactly what readers infer during their narrative experiences. For example, consider the legendary detective Sherlock Holmes. Without fail, Holmes displays considerable intellect in his exploits against clever (but not quite clever enough) criminals. Through the course of each of his adventures, readers come to root for Holmes to solve diabolical crimes against seemingly overwhelming odds. Despite this, Holmes is not easily classified as completely heroic; often he exhibits behaviors that run counter to how we might expect or want our heroes to act. As an example, in The Sign of Four (Doyle, 1890), Dr. Watson observes Holmes indulge his overwhelming addiction to cocaine:

Sherlock Holmes took his bottle from the corner of the mantelpiece and his hypodermic syringe from its neat morocco case. With his long, white, nervous fingers he 
adjusted the delicate needle, and rolled back his left shirt-cuff. For some little time his eyes rested thoughtfully upon the sinewy forearm and wrist all dotted and scarred with innumerable puncture-marks. Finally he thrust the sharp point home, pressed down the tiny piston, and sank back into the velvet-lined arm-chair with a long sigh of satisfaction... Three times a day for many months I had witnessed this performance, but custom had not reconciled my mind to it. (p. 1)

The reader, as well as Dr. Watson, may find this behavior to be problematic when it comes from their heroes. But does knowledge of Holmes as possessing negative traits (i.e., addiction) influence preferences and expectations about him as a heroic character? An important question for theories of narrative comprehension is how readers reconcile discrepancies between their expectations and preferences for characters, or perhaps whether, like Dr. Watson, they fail to reconcile contrary character information.

A large body of research has demonstrated that readers build models of characters based on text descriptions and use those models to generate predictions about future character behavior (see, e.g., Albrecht \& O'Brien, 1993; Campion, Martins \& Wilhelm, 2009; Just \& Carpenter, 1987; Peracchi \& O’Brien, 2004; Rapp \& Kendeou, 2007, 2009; Uleman, Hon, Roman \& Moskowitz, 1996; Zwaan \& Radvansky, 1998). For example, Rapp et al. (2001) provided participants with stories that potentially included descriptions of character behaviors, such as the following:

Rich was hired as a mailman for the route near Main Street. His job involved delivering mail to the local residents. He was responsible for making sure that everyone received their mail in a timely fashion. All day Rich would walk up and down people's sidewalks to put their mail in their mailboxes. At one particularly old house he would always hear a dog barking. This made him feel uncomfortable and he would scamper away from the house after delivering the mail.

The final sentence of this paragraph afforded readers the opportunity to build a model of Rich as a nervous or cowardly individual. Next, participants read a second episode involving Rich:

After work one day, Rich went to the movies. The theater he was sitting in was very crowded, and there were very few empty seats. A couple sitting behind Rich kept kicking his chair. They talked throughout the first half hour of the movie. Rich wondered if he could ask them to be quiet.

In one experiment, participants were asked to judge whether an outcome made sense given what they had read up until this point. Participants tended to agree more so with outcomes that were trait consistent (e.g., "Rich didn't ask them to be quiet.") rather than trait inconsistent (e.g., "Rich asked them to be quiet.") with the potentially encoded trait. In a second experiment, participants read the stories without an explicit judgment goal, and their reading times to the outcomes were recorded. Participants took longer to read traitinconsistent (e.g., "Rich turned around and exclaimed 'Stop talking." ") than to read trait-consistent (e.g., "Rich decided he'd better not start trouble.") outcomes. These findings indicate that readers build models for how characters will behave, which influences moment-by-moment reading as well as expectations for story outcomes.

To date, most projects have focused on the encoding and retrieval of relatively simple trait models, and several have investigated how readers deal with behavior that contradicts potential trait descriptions (for a review, see Gerrig \& Jacovina, 2009). However, few, if any, experiments have considered how readers might apply trait models when faced with multifaceted characters engaging in behaviors that are difficult to categorize as an exemplar of a single trait. In naturalistic texts, characters may, for example, behave in erratic friendly and hostile ways, conduct themselves rationally but also irrationally, or make both smart and naïve decisions within a single narrative situation. In these cases, it might be difficult for a reader to predict character activities and future story events. Readers may even hope that characters will exhibit behaviors that are inconsistent with traits they appear to possess. Using the previous example from Rapp et al. (2001), readers might prefer that Rich behave confidently, despite the story suggesting that he is a cowardly person. Readers may react similarly to Sherlock Holmes: Though text descriptions might suggest that Holmes's addiction should make it hard for him to think logically about a crime, readers no doubt hope that Holmes will deduce solutions despite his psychological state. These examples illustrate that readers often learn about characters from information that does not easily lend itself to the construction of a single, obvious trait inference.

In previous work, readers' wishes for future events, termed preferences, have been shown to influence the construction and application of inferences, even when those preferences run counter to events with inherently prescribed likelihoods. For example, Rapp and Gerrig (2006) presented participants with story descriptions for which the unfolding events, on their own, increased or decreased the likelihood that characters would succeed or fail at particular tasks (e.g., "The New York Times put [Charles's] efficient campaign several points ahead/behind in its final poll."). As with the Rapp et al. (2001) study, participants' judgments and reading times revealed difficulty with outcomes indicating success or failure when contexts suggested that such outcomes were unlikely. However, when stories also included information designed to encourage readers to root for characters (e.g., 
"Charles worked hard to help the underprivileged and underrepresented have a voice in government.") or against them ("Charles was corrupt, taking bribes and giving favors to companies that polluted the environment."), these patterns changed substantially. For example, outcomes associated with a low likelihood of success were generally processed as if they were unlikely to occur; however, when readers preferred characters in those unlikely situations to succeed, success was considered plausible (e.g., if participants rooted for Charles, they found the outcome "Charles was successful in his bid to become senator" plausible, even when the story context suggested an inevitable loss). These findings indicate that expectations for story events are based on the contingencies of unfolding story situations, with those expectations also reflecting the influence of preferences.

Thus, for more complex (but common) narrative situations, reader understanding of events is informed by contributions from multiple sources, including preferences and story contexts. However, the previous Rapp and Gerrig $(2002,2006)$ projects examined the likelihood of unfolding story events, rather than the types of models that readers constructed for the driving engines of those events - story characters. The present experiments investigated the inferences readers construct about character traits when those traits are informed by multiple, possibly conflicting, sources of information. Participants read short stories that potentially contained (a) preference statements designed to encourage readers to root for or against characters and (b) behavioral evidence for a positive or negative character trait. Consider this example:

Rich enjoyed being the only mailman in his small town.

Rich always made sure that the elderly folks received

their social security checks on time. All day Rich

would walk up and down the sidewalks to put their

mail in their mailboxes. He went to many different

homes owned and rented by many different people.

The second sentence in this text, which we refer to as a positive preference statement, was intended to encourage readers to prefer that good things happen to the protagonist. ${ }^{1}$ In contrast, consider a negative preference statement:

Rich often opened and stole elderly folk's social security checks without anyone having realized it.

\footnotetext{
${ }^{1}$ We note that the preference statement might also lead readers to expect that good things will generally happen to the protagonist, given their schematic understandings of story events. Simply, readers might hold the belief that good things happen to good people and bad things happen to bad ones. Contemporary accounts have not, as of yet, successfully distinguished between preferences as instantiating primarily schematic versus emotional representations with concomitant influences on processing. For the present investigation, either possibility would yield a similar influence for the purposes of investigating how conflicting information about characters impacts inferences about character traits and accompanying behaviors.
}

This version was intended to encourage readers to prefer that good things not happen to the protagonist. Additionally, we constructed a neutral preference statement that did not encourage a particular preference for or against the character:

\section{Rich delivered mail on the same route every day and knew the entire neighborhood well.}

Thus, preference statements could be positive, negative, or neutral. Participants also potentially received behavioral information intended to encourage the construction of a particular character trait. For example:

At one particularly old house Rich would always hear a small dog barking. This made him feel uncomfortable and he would scamper away from the house after delivering the mail.

The behavioral evidence provided here is intended to lead readers to infer that Rich is "cowardly" or "anxious." Note that the preference and the encoded trait could potentially match (e.g., negative preference statement, negative trait) or mismatch (e.g., positive preference statement, negative trait) in valence. In Experiments 1 and 2, participants were explicitly asked whether a character possessed a particular trait after reading each story, and in Experiment 3, we measured reading times for trait-consistent and trait-inconsistent story outcomes. Thus, we utilized offline judgments as well as reading times to test whether readers construct trait inferences as a function of both preference and behavioral evidence.

The design of the project afforded several predictions concerning these potential influences. The first set of predictions tested whether these influences exert a combined effect. An additive hypothesis suggests that when reader preferences and the behavioral trait evidence match in valence (i.e., negative preferences and negative evidence; positive preferences and positive evidence), readers should be more likely to expect that characters will possess similarly valenced traits, in comparison to when their expectations are informed solely by behavioral evidence. For example, if readers hope for Rich's failure, and Rich exhibits cowardly behavior, participants should believe him to be more cowardly than if they have simply read about Rich's cowardly behavior. A nonadditive hypothesis, in contrast, suggests that the addition of preference information should fail to enhance the certainty of readers' expectations beyond any trait inferences constructed from behavioral evidence.

However, there are cases, such as with our Sherlock Holmes example, in which preferences and behavioral evidence provide competing accounts of characters. A second set of predictions examined whether consistency 
between these sources affects readers' trait inferences. A valence alignment hypothesis suggests that when preferences and behavioral evidence match in valence, readers should show little difficulty in predicting future character behavior; mismatches across these cases, however, should reveal decrements in the ease with which readers infer particular trait models. A no-valence hypothesis, in contrast, predicts that matches or mismatches across preferences and behavioral evidence should matter little for readers' unfolding trait inferences.

Because we manipulated the valence of preference information and behavioral evidence, the materials also afforded the opportunity to examine whether, in general, positive or negative information exhibits a stronger influence on trait inferences. Under many conditions, individuals appear to allocate additional attention to negative information (i.e., Baumeister, Bratslavsky, Finkenauer \& Vohs, 2001; Egidi \& Gerrig, 2009; Peeters \& Czapinski, 1990). If this so-called negativity bias emerges, it might reveal higher agreement ratings for negative versus positive traits, and/or a greater influence of negative information on any combinatorial effects.

\section{Experiments 1A and 1B: trait judgments from preferences and evidence}

The goal of the first two experiments was to determine the influences of reader preferences and behavioral evidence on expectations for character traits. Participants read stories that included statements designed to encourage a like or a dislike for the main character, and that also included behavioral evidence for a particular trait. Following each story, participants were asked to indicate the degree to which they believed that the character held that particular trait. Information presented early in each story might exert an important influence on readers' processing of the unfolding text, helping them structure the nature of their mental representations (see, e.g., Gernsbacher, 1990). Thus, we tested whether the order of the presented preference and behavioral evidence would matter for any obtained effects. In Experiment 1A, preference information appeared before the behavioral evidence (i.e., the second and sixth sentences, respectively), and in Experiment 1B, behavioral evidence preceded the preference information (i.e., the fifth and eighth sentences, respectively).

\section{Method}

Participants A total of 66 University of Minnesota undergraduates participated in Experiment 1A, and 63 took part in Experiment 1B, all for course credit. All participants were native speakers of English.
Materials Participants read 18 narrative texts. The texts were adapted from Rapp et al. (2001), and as such had previously been normed to ensure that specific trait inferences were generated by readers as a function of the behavioral evidence provided in each story. Each 16sentence text focused on a single protagonist, organized into two 8-sentence episodes and averaging 200.70 words total $(S D=13.31$; see Appendices $\mathrm{A}$ and $\mathrm{B}$ for example texts). Nine of the texts introduced characters with negative traits (e.g., sloppy, rude), and nine introduced characters with positive traits (e.g., honest, eloquent). ${ }^{2}$ In Experiment $1 \mathrm{~A}$, the sixth sentence of each story provided behavioral evidence for the character possessing either a positive (e.g., intelligent, honest) or a negative (e.g., sloppy, belligerent) personality trait; in Experiment 1B, this information appeared as the fifth sentence. Positive and negative trait sentences were equated for length between texts $(M=15.11$ words for positive behavioral sentences, $S D=1.69 ; M=$ 16.00 words for negative behavioral sentences, $S D=3.74$ ), and $t$-tests revealed no differences in sentence length (all $t \mathrm{~s}<1$ ).

In the first episode of each story, we also inserted a preference sentence, which appeared as one of three versions: Positive preference statements provided information intended to encourage readers to like the character and root for his or her success (e.g., "He studied extremely hard for every exam, while also volunteering time at the local children's homeless shelter."); negative preference statements provided information intended to encourage readers to dislike the character and root against his or her success (e.g., "He passed most of his exams by stealing notes from his classmates instead of taking them himself."); neutral preference statements simply described the unfolding general situation (e.g., "The graduation was going to be held in the University's new basketball arena due to expected rain."). Within each text, the number of words was equated for the different statement types $(M=17.00$ words per positive preference, $S D=2.17 ; M=16.94$ words per negative preference, $S D=2.10 ; M=17.00$ words per neutral preference, $S D=2.11$ ), and $t$-tests revealed no differences in length (all $t \mathrm{~s}<1$ ). In Experiment 1A, the preference sentence appeared as the second sentence, and in Experiment 1B as the eighth (and final) sentence of the first episode. There were no other differences between the texts used in Experiments 1A and 1B.

After the first episode, participants read a second episode involving the same protagonist. This second episode did not include behavioral or preference information. After this second episode, participants were provided with a single statement describing the protagonist as possessing the

\footnotetext{
${ }^{2}$ The valence of the potential traits provided in each text was fixed, and was thus manipulated between items.
} 
relevant trait for that story (e.g., "Phillip is smart."; "Albert is sloppy."). These statements averaged 3.11 words ( $S D=$ 0.32 ) in length, and participants rated their agreement with each statement using a 7-point Likert-type scale ranging from 1 (strongly disagree) to 7 (strongly agree).

Design The procedures were identical for Experiments 1A and $1 \mathrm{~B}$. There were 3 versions of each of the 18 texts, in a 3 (preference sentence manipulated within items: positive, neutral, or negative) X 2 (trait valence manipulated between items: positive or negative) design. A Latin square was used to create three lists, with each text type appearing once on each list. Participants each received one list with the order of texts randomized within each list for each participant.

Procedure Participants received a 19-page packet, which included 1 page of instructions and 18 pages of texts. Each text page included the story on the front page and the relevant trait rating on the reverse side. Participants were instructed that they would read stories and rate the degree to which they agreed with a statement after each story. The statement to be rated was presented on the opposite side of each text page so that participants could not read it prior to or during the story. Participants were asked not to look at each rating statement before finishing each story, and also not to return to previous stories after they had made a rating. A single example was used on the instruction page to introduce participants to the task. Participants read at their own pace with no time limit for completion.

\section{Results and discussion}

We present the data and analyses for Experiment 1A, followed by those for Experiment 1B. All data were analyzed with participants $\left(F_{1}\right)$ and items $\left(F_{2}\right)$ as random variables. Table 1 presents mean agreement ratings from both experiments.

In Experiment 1A, participants' ratings were influenced by both preference information and behavioral evidence, as indicated by a significant interaction between the two factors $\left[F_{1}(2,130)=74.05, M S E=0.83, p<.001 ; F_{2}(2,16)=19.89\right.$, $M S E=0.42, p<.001]$. A main effect for trait information, significant by participants only $\left[F_{1}(1,65)=11.03, M S E=\right.$ $\left.1.03, p<.01 ; F_{2}<2\right]$, revealed higher agreement ratings for positive $(M=5.31, S D=0.61)$ than for negative traits $(M=$ 4.92, $S D=0.87)$. We observed a similar main effect for preference information $\left[F_{1}(2,130)=16.48, M S E=0.77, p<\right.$ $\left..001 ; F_{2}(2,16)=11.44, M S E=0.15, p<.01\right]$, with participants providing higher agreement ratings after reading stories containing positive $(M=5.29, S D=0.74)$ or neutral $(M=5.29, S D=0.80)$, as compared to stories containing negative $(M=4.80, S D=0.77)$, preference statements.
Table 1 Mean trait judgments as a function of trait and preference valence for experiments $1 \mathrm{~A}$ and $1 \mathrm{~B}$

Trait Valence

\begin{tabular}{|c|c|c|}
\hline Positive & & Negative \\
\hline $\mathrm{M}$ & SD & SD \\
\hline
\end{tabular}

Experiment 1A Preference Valence

\begin{tabular}{lcccc} 
Positive & 5.96 & 0.75 & 4.62 & 1.18 \\
Neutral & 5.79 & 0.97 & 4.79 & 1.20 \\
Negative & 4.17 & 1.20 & 5.34 & 0.88 \\
Experiment & $1 B$ & Preference Valence & & \\
Positive & 5.52 & 0.80 & 4.11 & 0.99 \\
Neutral & 5.25 & 0.91 & 4.42 & 0.90 \\
Negative & 4.06 & 1.00 & 4.95 & 0.79 \\
\hline
\end{tabular}

To determine the impact of valence on ratings, we conducted planned contrasts for each condition. Participants provided higher ratings for characters possessing positive traits when stories included positive preference information $(M=5.96, S D=0.75)$, as compared to negative preference information $(M=4.17, S D=1.20)[F 1(1,65)=90.10, M S E=$ $\left.2.36, p<.001 ; F_{2}(1,8)=30.47, M S E=0.95, p<.01\right]$, with no difference between positive and neutral information (both $F_{\mathrm{S}}<2$ ). Participants also provided higher ratings for characters possessing negative traits when stories included negative preference information $(M=5.34, S D=0.88)$, as compared to either positive $(M=4.62, S D=1.18)[F 1(1,65)=30.46$, $\left.M S E=1.13, p<.001 ; F_{2}(1,8)=11.12, M S E=0.42, p<.05\right]$ or neutral $(M=4.79, S D=1.20)[F 1(1,65)=16.72, M S E=$ $\left.1.22, p<.001 ; F_{2}(1,8)=4.44, M S E=0.63, p=.07\right]$ preference information.

This pattern of results was replicated in Experiment 1B. For that experiment, participants' trait ratings were again influenced by preference information and behavioral evidence, as supported by a significant interaction between the variables $\left[F_{1}(2,124)=55.52, M S E=0.81, p<.001 ; F_{2}(2,16)=11.85\right.$, $M S E=0.39, p<.01]$. We obtained a main effect of trait information $\left[F_{1}(1,62)=21.99, M S E=0.87, p<.01\right.$; $\left.F_{2}(1,8)=6.17, M S E=0.49, p<.05\right]$, with participants overall providing higher ratings for positive $(M=4.94, S D=$ $0.58)$ than for negative $(M=4.49, S D=0.64)$ traits. We also observed a main effect of preference information, significant by participants only $\left[F_{1}(2,124)=8.62, M S E=0.51, p<\right.$ $\left..001 ; F_{2}<1\right]$, with participants providing higher ratings after reading stories containing positive $(M=4.81, S D=0.65)$ and neutral $(M=4.84, S D=0.65)$, as compared to negative $(M=$ $4.50, S D=0.59)$, preference statements.

Planned contrasts tested the effects of valence on trait judgments, and the findings also replicated those from Experiment 1A. Participants provided higher ratings for characters possessing positive traits when stories included 
positive $(M=5.52, S D=0.80)$, as compared to negative $(M=$ 4.06, $S D=1.00)\left[F_{1}(1,62)=83.56, M S E=1.61, p<.001\right.$; $\left.F_{2}(1,8)=17.17, M S E=0.76, p<.01\right]$ or neutral $(M=5.25$, $S D=0.91)$ [significant by participants only: $F_{1}(1,62)=6.01$, $\left.M S E=0.76, p<.05 ; F_{2}<3.5\right]$, preference information. Participants also provided higher ratings for characters possessing negative traits when the stories contained negative $(M=4.95, S D=0.79)$, as compared to positive $(M=4.11$, $S D=0.99)\left[F_{1}(1,62)=27.90, M S E=1.60, p<.001 ; F_{2}(1\right.$, $8)=7.15, M S E=0.85, p<.05]$ or neutral $(M=4.42, S D=$ $0.90)$ [significant by participants only: $F_{1}(1,62)=19.79$, $\left.M S E=0.87, p<.001 ; F_{2}<3.50\right]$, preference information.

The findings from both Experiments $1 \mathrm{~A}$ and $1 \mathrm{~B}$ provided support for the valence alignment hypothesis: Participants provided higher trait ratings when preference information was of the same valence as the behavioral evidence suggesting that trait. However, the findings only revealed partial support for the additive hypothesis. Readers' ratings for positive traits enjoyed no additional contribution from positive preferences, but ratings for negative traits did increase with negative preferences. Specifically, for positive trait ratings, no differences emerged between positive and neutral preference conditions; in contrast, for negative trait ratings, differences were observed between negative and neutral preference conditions. These differential findings might be a function of a negativity bias, but if so, that bias is relatively modest; participants tended to provide overall higher ratings for characters and stories that included positive rather than negative traits. In sum, the observed effects revealed an interaction between the valence of reader preferences and behavioral evidence for particular character traits.

Although preference information exerted a measurable influence in both experiments, we note that the participants in Experiment $1 \mathrm{~B}$ provided slightly lower overall trait ratings than did participants in Experiment 1A. ${ }^{3}$ This result is somewhat counterintuitive, since one might expect that

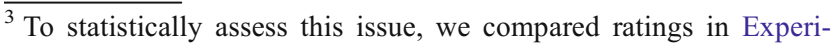
ments $1 \mathrm{~A}$ and $1 \mathrm{~B}$ using an ANOVA with Experiment as a betweenparticipants factor. Overall, there was a main effect of trait $\left[F_{1}(1\right.$, $127)=30.38, M S E=1.12, p<.01 ; F_{2}(1,16)=5.00, M S E=1.00$, $p<.05$ ], since ratings in Experiment $1 \mathrm{~A}$ for positive $(M=5.31, S D=$ $0.61)$ and negative $(M=4.92, S D=0.87)$ traits were generally higher than the ratings in Experiment 1B for positive $(M=4.94, S D=0.58)$ and negative $(M=4.49, S D=0.64)$ traits. We also observed a main effect of preference statements $\left[F_{1}(2,254)=24.72, M S E=0.64, p<\right.$ $\left..001 ; F_{2}(2,32)=4.67, M S E=0.30, p<.05\right]$, with participants in Experiment $1 \mathrm{~A}$ providing higher ratings for texts containing positive $(M=5.29, S D=0.74)$, neutral $(M=5.29, S D=0.79)$, and negative $(M=4.76, S D=0.77)$ preference information, as compared to Experiment 1B's mean trait ratings for positive $(M=4.81, S D=$ $0.65)$, neutral $(M=4.84, S D=0.65)$, and negative $(M=4.50, S D=$ $0.59)$ preference information. We observed an interaction between experiments $\left[F_{1}(1,127)=17.77, M S E=1.70, p<.001 ; F_{2}(1,16)=\right.$ $4.58, M S E=0.88, p<.05]$, but, of crucial importance for our order effect analysis, we did not observe the three-way interaction of trait by preference by experiment (both $F \mathrm{~s}<1.5$ )
}

the information provided earlier in the story would have the strongest influence on the development of a trait model. However, the findings from Experiment $1 \mathrm{~A}$ indicate that the presentation of preference information first, rather than behavioral evidence first as in Experiment 1B, resulted in higher trait ratings. This observation leads to the intriguing notion that preferences, on their own, might influence readers' trait models. We note that although preference statements might be utilized by readers to encode potential traits, the preference statements included in these experiments were not specifically associated with, nor did they provide directly relevant behavioral evidence for, the tested traits (e.g., if Rich is stealing, how does that inform expectations that he might be cowardly?). The most relevant information in the texts for constructing trait models might be the similarity of a preference's valence to a tested trait (e.g., stealing and being cowardly are both negative traits). This line of reasoning led us to test, in Experiments $2 \mathrm{~A}$ and $2 \mathrm{~B}$, whether preference information might encourage expectations for similarly valenced traits, in the absence of relevant behavioral evidence for those traits.

\section{Experiments 2A and 2B: trait judgments solely from preferences}

Do readers construct trait inferences solely on the basis of their preferences for characters? The goal of the next two experiments was to test whether readers would continue to have expectations for character traits when behavioral evidence for those traits was eliminated. According to the valence alignment hypothesis, when the valence of a preference statement matches the valence of a trait, participants should provide higher trait ratings than when those valences mismatch. In this set of experiments, those traits (and their inherent valences) were only introduced when participants were explicitly asked whether a character possessed that trait. If readers can construct trait inferences solely from preferences, we would expect higher ratings to trait judgments when preferences matched the valence of those tested, but never demonstrated, traits. Evidence indicating that readers do not construct inferences solely from preferences would instead be more consistent with the no-valence hypothesis.

As before, we also manipulated the materials to observe any potential effects of order and to preserve fidelity with the previous experiments. In Experiment 2A, preference information appeared as the second sentence in the story; in Experiment 2B, preference information appeared as the eighth and final sentence of the first episode. We also note these positions were the same as those utilized in the previous experiments. 


\section{Method}

Participants A total of 32 University of Minnesota undergraduates participated in Experiment $2 \mathrm{~A}$ and 31 in Experiment 2B, all for course credit. All participants were native speakers of English.

Materials The texts used in Experiments 2A and 2B were the same as those in Experiment 1A and 1B, respectively, with one exception (see Appendices A and B). Each text was modified so that the behavioral trait evidence (e.g., "They were buried under old candy wrappers, crumpled magazines, and some dirty laundry.") was replaced with a control sentence providing no direct behavioral evidence for any trait (e.g., "Albert's classmates had suggested meeting in the local coffee shop by the library."). Control sentences $(M=14.67$ words per sentence, $S D=2.79)$ were matched for length with the sentences they replaced $(M=$ 14.67 words per sentence, $S D=2.79$ ). Control sentences appeared as the sixth sentence in Experiment 2A, and as the fifth sentence in Experiment 2B, in the positions previously occupied by behavioral evidence. No other changes were made to the texts.

Design The design was identical to that used in Experiments $1 \mathrm{~A}$ and $1 \mathrm{~B}$.

Procedure The procedure was identical to that used in Experiments $1 \mathrm{~A}$ and $1 \mathrm{~B}$.

\section{Results and discussion}

Table 2 presents the mean agreement ratings observed in Experiments $2 \mathrm{~A}$ and $2 \mathrm{~B}$. It is important to note that although participants did not receive behavioral evidence

Table 2 Mean trait judgments as a function of preference valence (without trait evidence) for experiments $2 \mathrm{~A}$ and $2 \mathrm{~B}$

Trait Valence

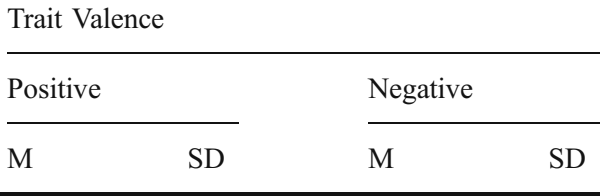

Experiment 2A Preference Valence

\begin{tabular}{lcccc} 
Positive & 5.06 & 0.83 & 2.68 & 0.89 \\
Neutral & 4.78 & 0.74 & 2.66 & 0.86 \\
Negative & 3.75 & 0.66 & 3.88 & 1.11 \\
Experiment & 2B Preference Valence & & \\
Positive & 5.11 & 0.71 & 2.45 & 0.85 \\
Neutral & 4.78 & 0.54 & 2.46 & 0.95 \\
Negative & 3.60 & 1.07 & 3.78 & 1.21 \\
\hline
\end{tabular}

for traits, the trait judgment statements were the same as in Experiments 1A and 1B (i.e., "Albert is sloppy."). Hence, we continue to differentiate the particular traits that participants rated as positive and negative, although no behavioral evidence, positive or negative, was provided for them within the texts. We first provide analyses for Experiment 2A, followed by Experiment 2B.

In Experiment 2A, as evidence of the impact of preferences on traits, we observed a significant interaction between trait and preference valence $\left[F_{1}(2,62)=41.23\right.$, $M S E=0.74, p<.001 ; F_{2}(2,16)=20.60, M S E=0.39, p<$ $.001]$. We also obtained a significant main effect of trait valence $\left[F_{1}(1,31)=123.33, M S E=0.83, p<.01\right.$; $\left.F_{2}(1,8)=44.27, M S E=0.60, p<.001\right]$, with participants providing higher ratings for positive $(M=4.53, S D=0.49)$ than for negative $(M=3.07, S D=0.62)$ traits. No main effect of preference information was observed $\left(F_{\mathbf{S}}<1\right)$.

Planned contrasts were conducted to further elaborate the effects. Participants provided higher ratings for positive traits when stories included positive preference $(M=5.06$, $S D=0.83)$ rather than negative preference $(M=3.75, S D=$ 0.66) $\left[F_{1}(1,31)=63.59, M S E=0.87, p<.001 ; F_{2}(1,8)=\right.$ $6.99, M S E=1.68, p<.05]$ information. Ratings for positive traits did not differ, however, when stories included positive or neutral preference information (both $F \mathbf{s}<3$ ). Participants also provided higher ratings for negative traits when stories included negative preference information $(M=3.88, S D=$ 1.11) than when they contained either positive $(M=2.68$, $S D=0.89)\left[F_{1}(1,31)=19.90, M S E=2.31, p<.001 ; F_{2}(1\right.$, $8)=9.79, M S E=1.39, p<.05]$ or neutral $(M=2.66, S D=$ 0.86) $\left[F_{1}(1,31)=33.05, M S E=1.44, p<.001 ; F_{2}(1,8)=\right.$ $11.48, M S E=1.10, p<.05]$ preference information. We note that participants' ratings when negative preference information was provided indicated that they were somewhat undecided as to whether the character truly had a negative trait $(M=3.88$, with 4 the midpoint for the rating scale). By comparison, in the presence of neutral or positive preference information, participants' ratings of negative traits suggested relative disagreement with the trait $(M=$ 2.67). These findings run counter to any potential negativity bias.

Experiment 2B generally replicated the results. A significant interaction was observed between trait and preference valence $\left[F_{1}(2,60)=51.16, M S E=0.73, p<\right.$ $\left..001 ; F_{2}(2,16)=24.51, M S E=0.44, p<.001\right]$. We obtained a significant main effect of trait valence $\left[F_{1}(1,30)=107.70, M S E=1.10, p<.01 ; F_{2}(1,8)=\right.$ 123.96, $M S E=0.29, p<.001]$, with participants providing higher ratings for positive traits $(M=4.50, S D=0.52)$ than for negative traits $(M=2.90, S D=0.72)$. There was no main effect of preference (both $F_{\mathrm{s}}<1$ ).

Planned contrasts revealed findings similar to those reported in Experiment 2A. Participants provided higher 
ratings to positive traits when stories included positive preference information $(M=5.11, S D=0.71)$, as compared to either negative $(M=3.60, S D=1.07)\left[F_{1}(1,30)=46.07\right.$, $M S E=1.53, p<.001 ; F_{2}(1,8)=13.36, M S E=1.59, p<$ .01 ] or neutral $(M=4.78, S D=0.54)$ [significant by participants only: $F_{1}(1,30)=4.61, M S E=0.70, p<.05$; $\left.F_{2}<2\right]$ preference information. Participants also provided higher ratings to negative traits when stories included negative preference information $(M=3.78, S D=1.21)$, as compared to either positive $(M=2.45, S D=0.85)\left[F_{1}(1\right.$, $30)=26.86, M S E=2.05, p<.001 ; F_{2}(1,8)=8.58, M S E=$ $1.65, p<.05]$ or neutral $(M=2.46, S D=0.95)\left[F_{1}(1,30)=\right.$ 41.96, $M S E=1.29, p<.001 ; F_{2}(1,8)=10.72, M S E=1.41$, $p<.05]$ preference information. Again, participants seemed undecided as to whether a character truly had a negative trait, despite the presence of the negative preference information ( $M=3.78$, with 4 the midpoint for the rating scale). In comparison, in the presence of neutral or positive preference information, participants tended to disagree with negative traits $(M=2.46)$. Again, these pieces of evidence run counter to a possible negativity bias.

Overall, the findings of Experiment 2B replicated those of Experiment 2A, with trait ratings quite systematic, despite the absence of suitable behavioral evidence for traits. Participants provided higher ratings to traits that matched preferences on valence, as compared to when those traits and preferences mismatched, consistent with the valence alignment hypothesis. This was especially apparent for ratings of positive traits (i.e., "Chris is honest."); in contrast, when negative preference statements were included in the texts, participants appeared somewhat unsure as to whether characters possessed negative traits. Thus, readers seem more reticent to endorse negative traits than positive ones when behavioral evidence is unavailable for such decisions. We also note that these results were similar regardless of whether the preference information was provided earlier or later in the texts.

Overall, the results across the four experiments indicate that participants' inferences about characters incorporate knowledge about behavioral evidence as well as their preferences for unfolding story events. However, the findings thus far were a function of judgments that readers made after the stories were completed. Any evidence of inferences, therefore, might not reflect obligatorily constructed models of characters in the service of understanding the text events, but rather reflect task demands that encouraged inference construction. Additionally, there is no way of ascertaining from the present data whether any

\footnotetext{
${ }^{4}$ We compared the mean agreement ratings in Experiments $2 \mathrm{~A}$ and $2 \mathrm{~B}$ using an ANOVA with Experiment as a between-participants factor. No significant between-experiment effects were observed (all $F$ s $<$ $1.5)$.
}

potential inferences were constructed prior to participants being asked to make trait judgments. To address these issues, we next evaluated whether the complexity of characters, as a function of multiple sources of character information, exerts an observable influence on moment-bymoment reading processes.

\section{Experiment 3: reading times to story outcomes}

Previous experiments (e.g., Rapp et al., 2001) have demonstrated that readers build trait models during reading and apply those models in attempts to comprehend a text. This finding has been examined with respect to reading times, with participants taking longer to read story outcomes that are inconsistent, rather than consistent, with previously encoded traits (e.g., Albrecht \& O’Brien, 1993; Rapp \& Kendeou, 2009). Although we inferred that the judgments obtained in Experiments 1 and 2 were the result of similar processes occurring during comprehension, the experimental tasks limited our ability to ascribe the observed effects to online processes with any certainty. In Experiment 3, we specifically investigated the potential additive effects of preferences and of behavioral evidence information on the processes readers engage in during comprehension. To do this, we modified the materials from Experiment 1A, employing only positive and negative preference sentences. We tested whether matches between the valences of a preference and a trait would influence participants' processing of trait-consistent and traitinconsistent behavior.

\section{Method}

Participants A total of 52 University of Minnesota undergraduates participated in Experiment 3 for course credit. All were native speakers of English.

Apparatus Participants read the stories on PCs running EPrime software. The stories were presented on a 15 -in. Dell CRT color monitor, and participants responded using the keyboard. The E-Prime software recorded participants' keypresses during the experimental tasks, which included latencies between keypresses (in milliseconds) and the actual keys pressed. Sentences appeared as standard black type on a white background in the center of the screen.

Materials Participants read the 18 narrative texts from Experiment 1A. Each text, as before, focused on a single protagonist, was organized into two eight-sentence episodes, and always contained behavioral information in the 6th sentence designed to elicit a specific trait inference. The 2nd sentence of each story provided preference informa- 
tion, specifically manipulated to potentially align with the valence of the trait. For matching preference texts, the valence of the preference matched that of the trait. For example, participants could read a positive preference sentence (e.g., "He studied extremely hard for every exam, while also volunteering time at the local children's homeless shelter.") and subsequently read behavioral evidence for a positive trait (e.g., intelligent: "Philip graduated with the highest honors, because he earned a 4.0 GPA."). Likewise, for stories containing behavioral evidence for a negative trait, participants would have previously read a negative preference sentence. For mismatching preference texts, the preference mismatched the valence of the trait. In this condition, for example, participants could read a negative preference statement (e.g., "He passed most of his exams by stealing notes from his classmates instead of taking them himself.") prior to receiving behavioral evidence for a positive trait (or conversely, a positive preference statement followed by a negative trait). ${ }^{5}$

Following the first episode, participants read a second eight-sentence episode involving the protagonist that described a situation to which the inferred trait might apply (see Appendix A). For each story, we wrote two outcome sentences (i.e., the 15th sentence of the story); trait-consistent sentences described the character behaving in a manner consistent with the earlier trait evidence, and trait-inconsistent sentences described the character behaving in a manner inconsistent with the earlier evidence. We also constructed a 16th, concluding sentence for each story. We equated both the 15 th $(M=10.29$ words across all stories $)$ and 16th $(M=10.03$ words across all stories) sentences for number of words.

Finally, we created 18 filler and 2 practice stories that were similar in structure and length to the experimental texts but did not contain information pertaining to character traits. These stories were also 16 sentences long. All experimental, filler, and practice stories were followed by a comprehension question that could be answered with either a "yes" or "no" response.

Design There were four versions of each of the experimental texts, in a 2 (valence of preference and trait, manipulated within items: valence matched or mismatched) $\times 2$ (outcome sentence manipulated between items: trait consistent or inconsistent) design. A Latin square was used to create four lists, with each text type appearing once on each list. Participants each received one list, with the texts presented to them in a random order. The assignment of participants to the lists was balanced so that each item was read an equal number of times. Comprehension

\footnotetext{
${ }^{5}$ As in the previous experiments, the valence of the potential trait provided in each text was fixed, manipulated between items.
}

questions were also balanced between lists, so that 18 questions required a "yes" answer and 18 required a "no" answer.

Procedure Participants were seated at the computer and instructed that they would read the stories one sentence at a time at their own pace and would answer a comprehension question at the end of each story. Participants then completed two practice stories to familiarize themselves with the experimental procedure. Each story was introduced with a screen that read, "When you are ready, press the NEXT key for the next story." Participants would then advance to each sentence in the story by pressing the "A" key, which was labeled as the NEXT key. After participants had read the final sentence of a story, a tone sounded and the string “****** QUESTION $* * * * *$ " appeared for $1,000 \mathrm{~ms}$. A comprehension question then appeared, and participants would either press the "J" key, labeled as YES, or the "K" key, labeled as NO. There was no time limit for participants to answer the question.

\section{Results and discussion}

To account for differences in length for the outcome sentences between texts, we transformed raw sentence reading times into unstandardized, length-adjusted residual scores and conducted analyses on these scores (cf. Ferreira \& Clifton, 1986; Rapp, 2008; Trueswell, Tanenhaus \& Garnsey, 1994). For ease of presentation, all reading times are presented as raw scores, because the analyses for raw and residual reading times demonstrated generally similar patterns. Reading times greater than 2.5 standard deviations above the mean for each participant were removed, which resulted in a loss of $2.7 \%$ of the data. On average, participants correctly answered $90.7 \%$ of the comprehension questions. Table 3 presents mean reading times for the outcome sentences.

We did not observe any main effects of story outcome or preference-trait match (all $F_{\mathrm{S}}<3.5$ ). However, we observed an interaction between preference-trait valence and story outcome, significant by both participants and items $\left[F_{1}(1\right.$, $51)=5.73, M S E=421,748, p<.05 ; F_{2}(1,17)=5.53$,

Table 3 Mean reading times (in milliseconds) for outcome sentences in Experiment 3

\begin{tabular}{llllll}
\hline & \multicolumn{2}{c}{ Trait Consistent Outcome } & & \multicolumn{2}{c}{ Trait Inconsistent Outcome } \\
\cline { 2 - 3 } \cline { 5 - 6 } & $\mathrm{M}$ & $\mathrm{SD}$ & & $\mathrm{M}$ & $\mathrm{SD}$ \\
\hline Preference & and Trait Valence & & & \\
Match & $2,182.68$ & 572.77 & & $2,252.24$ & 602.27 \\
Mismatch & $2,272.13$ & 665.66 & & $2,218.78$ & 523.71 \\
\hline
\end{tabular}


$M S E=223,143, p<.05]$. Participants showed the least difficulty processing trait-consistent outcome sentences when the preceding text included a preference and behavioral evidence that were matched for valence. In comparison, slow-downs were observed for trait-consistent story outcomes when the preceding preferences and behavioral evidence mismatched [a 89.45 -ms difference, significant by participants only: $F_{1}(1,51)=6.26, M S E=397,992, p=.01$; $\left.F_{2}<3\right]$. Also, as compared to the trait-consistent, valencematched condition, participants demonstrated slowdowns when story outcomes were trait inconsistent, regardless of whether the preference and the behavioral evidence were matched in valence [a 69.56-ms difference, significant by participants and marginal by items: $F_{1}(1,51)=9.95, M S E=$ $\left.831,692, p<.01 ; F_{2}(1,17)=3.94, M S E=339,321, p=.06\right]$ or mismatched in valence [a 36.10 -ms difference, significant by participants only: $F_{1}(1,51)=3.75, M S E=389,898, p=$ $.05 ; F_{2}<2$ ]. No other simple effect comparisons were significant (all $F_{\mathrm{S}}<2$ ).

These findings provide convergent evidence that the combinatorial effects of preferences and behavioral evidence influenced moment-by-moment comprehension of the texts. Readers' processing of unfolding events reflected difficulty when characters exhibited complexity, such that the characters were less easily distinguished as possessing a single trait. Participants slowed down to read outcomes when (a) the previous information (i.e., preference information and behavioral evidence) ran counter to that outcome or (b) the previous information failed to provide a single consistent characterization of the protagonist. These findings are in line with both the additive and valence alignment hypotheses.

We also analyzed the 16th and final sentence for each story, which immediately followed the outcome sentence, since previous research has sometimes revealed spill-over processing effects for sentences that follow inconsistent information (e.g., Albrecht \& O'Brien, 1993; Rapp, 2008). In this experiment, participants were generally quick to recover from inconsistent outcome information, with no reading time effects for this final sentence (all $F \mathrm{~s}<2$ ).

\section{General discussion}

Previous work has demonstrated that readers construct and apply trait models of characters in the service of narrative comprehension (Rapp \& Gerrig, 2002, 2006; Rapp et al., 2001). The goal of the present project was to investigate the inferences readers can generate about character traits as a function of potentially conflicting sources of information. In Experiments 1A and 1B, we examined the combined influences of behavioral evidence for traits and information designed to encourage preferences for or against characters on trait judgments. In Experiments 2A and 2B, we focused solely on the influence of preference information for those judgments. Across these experiments, participants provided higher trait ratings when information provided in the text matched the valence of the tested information. Specifically, trait ratings were higher when behavioral evidence and reader preferences matched, as compared to mismatched, the valence of a tested trait. Strikingly, when behavioral evidence was completely removed from the stories, participants continued to provide higher ratings for traits that matched rather than mismatched the valence of the preference in that story. These judgment effects were obtained regardless of the order of the presentation of critical statements.

In Experiment 3, we measured reading times for story outcomes that reflected either trait-consistent or traitinconsistent events. Participants took longer to read outcomes that did not receive uniform support from the preceding preference information and behavioral evidence. And when uniform support was provided, participants took longer to read outcomes that were inconsistent with the inferable trait. Thus, moment-by-moment reading times changed as a function of the complexity of characters and the ease with which a trait could be generated as a result of any such complexity. These findings nicely complement the earlier experiments, demonstrating that nuanced characters influence not only readers' explicit judgments about traits, but also the readers' unfolding comprehension of text content. This evidence is also consistent with the notion that readers construct trait inferences of characters during reading and attempt to apply these inferences as part of their narrative experiences (e.g., Rapp et al., 2001).

These findings supported two hypotheses that speak directly to the contributions of consistent or discrepant information offered on behalf of story characters. The additive hypothesis suggests that reader preferences and behavioral evidence can exert a combined, cumulative effect on trait models. Three pieces of evidence sustained this hypothesis. First, trait ratings were higher when stories contained preferences and behavioral evidence of similar valence, relative to when readers were simply provided with behavioral evidence (and neutral preference information). Second, trait ratings were higher when those judgments were based on both preferences and evidence (Exps. $1 \mathrm{~A}$ and $1 \mathrm{~B}$ ) than when readers based those judgments only on preferences (Exps. 2A and 2B). Thus, when confronted with descriptions of characters, readers are more likely to endorse traits that receive support from several narrative elements (e.g., relevant character behaviors and emerging preferences for story events). Third, reading times for traitbased story outcomes revealed processing decrements when protagonist accounts offered competing considerations. 
However, when information about protagonists was consistent, readers exhibited less difficulty with unfolding trait descriptions.

The findings also support the notion that readers' trait models are directly informed by the valences of the information they read about, as outlined by the valence alignment hypothesis. As evidence of this, participants' agreement ratings were highest when the preference information matched the behavioral evidence in valence (and, conversely, those ratings were low for valence mismatches). In fact, valence was so crucial to judgments that readers' ratings were higher when their preferences for characters matched rather than mismatched the traits that were queried, despite having read no evidence whatsoever for those traits in the stories. Reading times also revealed benefits for the processing of outcomes when previous information was consistent in valence. Across all three experiments, readers' character models were informed by multiple aspects of narratives, even aspects that might not be directly relevant for making evidence-based decisions about character traits (e.g., preferences).

Finally, we observed little in the way of strong evidence for a negativity bias in character judgments. Participants provided higher agreement ratings for positive than for negative traits, and in Experiments $2 \mathrm{~A}$ and 2B were somewhat reticent to endorse negative traits whatsoever. One possibility is that the explicit rating task could have encouraged readers to critically analyze characters, which may have led to hesitation in ascribing negative traits to characters they knew relatively little about. Unfortunately, Experiment 3 did not employ a design that targeted the roles of negative versus positive traits and readers' attention to behavioral evidence or to preference statements as a function of such a valence manipulation. One goal of future work should be to examine how readers' moment-by-moment experiences of text information might reflect attentional changes as a function of a variety of factors, including the specific valences of descriptions and preferences.

Although we found evidence that readers' ratings and reading times were a function of their desires for character success and of explicit descriptions of characters' behaviors, the question remains as to how readers represent contradictory information about characters in memory. Previous research considered this issue by evaluating processing activities when readers learn about characters actually behaving in inconsistent ways. For example, O'Brien and colleagues (Albrecht \& O'Brien, 1993; Hakala \& O’Brien, 1995; O’Brien, Rizzella, Albrecht \& Halleran, 1998) presented participants with texts describing characters and their behaviors (e.g., Mary is a vegetarian). In their analyses, participants slow down when reading sentences that describe characters behaving inappropriately (e.g.,
"Mary ordered a cheeseburger and fries."), even if prior information suggested that those behaviors might be plausible (e.g., "Mary was a vegetarian in the past, but not currently."). Thus, readers' representations of characters appear to reflect retrieval processes that invoke earlier encoded trait models (e.g., Mary is a vegetarian), with those models brought to bear during moment-by-moment reading. One possibility, then, is that mental representations of characters might not easily include information about contradictions, but instead encode more definite forms of trait models (e.g., vegetarian or not vegetarian, good or bad).

Thankfully, recent work has suggested that readers can, under some conditions, revise what they know to construct more-or-less definite representations about characters (e.g., Guéraud, Harmon \& Peracchi, 2005; Rapp \& Kendeou, 2007, 2009). For example, in a series of experiments, participants read stories that provided behavioral evidence for a trait (e.g., "[Albert's shoes] were buried under old candy wrappers, crumpled magazines, and dirty laundry.") that was immediately followed by a refutation. Participants were more likely to revise their trait models (e.g., sloppy) if refutations included causal explanations (e.g., "Albert cared about the condition of his room but had only moved into the apartment yesterday.") than if refutations simply disregarded earlier evidence without sufficient explanation (e.g., "Albert didn't care about keeping his room clean, and this is how it usually would look."). When contradictory information lacked sufficient explanation, readers either deferred to the originally presented information or failed to endorse one character trait over another, keeping multiple and even conflicting (e.g., sloppy and clean) possibilities plausible (Rapp \& Kendeou, 2007). Contradictory information, therefore, can lead readers to revise and elaborate their representations of characters, or can result in readers deferring endorsements until more information is available.

But exactly how specific are the trait models that readers might infer from contradictory information? Previous research has been inconsistent on this point; some work has shown that readers make relatively general inferences about characters' behaviors and emotions (e.g., Gygax, Garnham \& Oakhill, 2004; Gygax, Oakhill \& Garnham, 2003), while other projects have shown specificity with respect to readers' inferences about characters' emotions and traits (e.g., Gernsbacher, Goldsmith \& Robertson, 1992; Gernsbacher, Hallada \& Robertson, 1998; Gernsbacher \& Robertson, 1993; Rapp et al., 2001). In the present project, participants provided higher ratings for traits that were matched rather than mismatched on valence with preferences, and slower reading times to outcomes when trait evidence was mismatched rather than matched on valence with preferences, despite those preference statements providing little 
in the way of evidence for the traits actually being queried. While this pattern is consistent with the notion that participants might have considered characters as "bad" or "good," both ratings of characters as possessing those traits and reading times for the story outcomes nevertheless reflected the combinatorial influences of both preferences and behavioral evidence. What this might suggest is that the degree to which readers encode general or specific traits about characters might reflect both how directly or easily a particular trait model can be inferred from evidence, as well as how motivated the reader is to construct such a model. In fact, work in our lab has begun investigating whether particular task goals and methodologies might differentially influence the specificity of the representations that readers build for characters (Rapp \& Mensink, in press; Sparks \& Rapp, 2011). Future work might utilize converging evidence from multiple methodologies (e.g., judgment tasks, reading time tasks, and naming) to investigate the nature of mental representations developed from contradictory information (see Rapp, 2008, for a discussion).

The issue of how readers represent and comprehend text contradictions, inaccuracies, and inconsistencies is an important one. Much of the work on text comprehension has focused on the text dimensions that are encoded during reading and that exert an influence on the products of those encoding processes (e.g., Zwaan, Langston, \& Graesser, 1995; Zwaan, Magliano, \& Graesser, 1995; Zwaan \& Radvansky, 1998; Zwaan \& Rapp, 2006). Across these projects, shifts in dimensions, such as time or space, or discrepancies in character behavior have resulted in processing decrements (e.g., Albrecht \& O'Brien, 1993; Levine \& Klin, 2001; Morrow, Greenspan \& Bower, 1987; O’Brien et al., 1998; Zwaan, 1996). Thus, the bulk of this work has used inconsistencies in text dimensions as a means of evaluating comprehension difficulties, characterizing them as potential problems for readers to overcome in their attempts at understanding what they read.

The present project, in contrast, conceptualizes these types of inconsistencies as occurring regularly during our everyday experiences with fiction. Readers commonly encounter descriptions that might be classified as event shifts in causal or computational analyses but that, under naturalistic reading conditions, actually make texts richer and more interesting (see, e.g., Campion et al., 2009). For example, popular stories often involve heroes behaving badly (e.g., James Bond from the Ian Fleming novel series; Dr. Gregory House on the Fox program House; Dexter from the HBO television series) or villains exhibiting sympathetic qualities (e.g., Darth Vader from Star Wars; Gollum from The Lord of the Rings). Even classic literary characters such as Dickens's Scrooge and Salinger's Holden Caulfield exhibit both positive and negative traits, which makes them interesting characters to read about over and over again. Understanding the ways in which readers infer trait models for such complex characters as these can help enrich existing accounts of narrative comprehension and memory representation, as well as explain the actual kinds of experiences we have with the most popular and widely cited classics in the literary canon.

Author Note We thank Sally Polzin for her assistance in data collection. We also thank three anonymous reviewers for their comments on earlier versions of the manuscript. The first author's contribution was supported by an Institute of Education Sciences Interdisciplinary Education Sciences Training Program Grant (R305C050059) and by funding received from the University of Minnesota's Office of the Vice President for Research and from the College of Education and Human Development.

\section{Appendix A: sample negative trait story for experiments $1 \mathrm{~A}, 2 \mathrm{~A}$, and 3}

Episode 1 (sloppy)

Albert was getting ready to meet his assigned group to work on their final project for psychology class.

\section{Positive preference sentence}

Albert's family was very poor and he'd lose his college scholarship unless he got an 'A' on the project.

\section{Neutral preference sentence}

His group had started the project at the beginning of the semester and was making the final changes to it.

\section{Negative preference sentence}

Albert hadn't contributed at all but planned on putting his name first to take the bulk of the credit.

Episode 1 continued

He began getting dressed for the day. He pulled a sweater over his head. Then he began to look for his shoes.

\section{Trait sentence (Exps. $1 A$ and 3)}

They were buried under old candy wrappers, crumpled magazines, and some dirty laundry. 


\section{Control sentence (Exp. 2A)}

Albert's classmates had suggested meeting in the local coffee shop by the library.

Episode 1 continued

Albert loaded up his backpack with school materials. Then he put on his jacket and walked out of the house to catch the bus downtown.

Episode 2 (Exps. 1A and 2A)

Later that week, Albert went to see a movie. He knew it would be easiest if he took the bus to the movie theater. It was a long bus ride, and Albert stared out the window watching cars go by. He was just about to fall asleep when the bus driver announced his stop. Albert stood up and headed to the exit in the back of the bus. As he waited for the bus to come to a halt, he noticed a sign informing riders that bus fares would soon increase. Albert hoped the fare increase wouldn't be too drastic. The bus slowed to a stop and Albert exited the bus.

\section{Trait judgment question}

Statement: Albert is sloppy.

Episode 2 (Exp. 3)

Later that week, Albert went to see a movie. Albert had to take the bus to go to the movies. He bought a newspaper to read during the ride to the theater. Albert had finished leafing through the paper when his stop was announced. Albert put the newspaper on the seat next to him. As he waited for the bus to stop, he noticed a sign asking riders not to leave garbage on the bus.

\section{Trait-consistent outcome and spillover sentence}

Albert ignored the sign and got off the bus.

Someone else would come to pick up the newspaper.

Trait-inconsistent outcome and spillover sentence

Albert picked up the newspaper to throw away later.

He wanted to help keep the bus clean.

\section{Comprehension}

Did Albert read a sign on the bus? (Yes)
Appendix B: sample positive trait story for experiments $1 \mathrm{~B}$ and $2 \mathrm{~B}$

Episode 1 (Smart)

Philip was graduating from college. Each student received four tickets to invite parents and friends to the ceremony. Philip also had to buy a graduation gown and cap for the event. Everyone at the ceremony was happy and proud of the graduating class.

Trait sentence (Exp. 1B)

Philip graduated with the highest honors, because he earned a 4.0 GPA.

Control sentence (Exp. 2B)

The ceremony lasted for almost two hours, but it passed by quickly.

Episode 1 continued

After the ceremony, Philip took pictures with family and friends. Then they went out to dinner to celebrate this big event.

\section{Positive preference sentence}

Philip studied extremely hard for every exam, while also volunteering time at the local children's homeless shelter.

\section{Neutral preference sentence}

The graduation was going to be held in the University's new basketball arena due to expected rain.

\section{Negative preference sentence}

Philip passed most of his exams by stealing notes from his classmates instead of taking them himself.

Episode 2

Philip enjoyed playing poker with a group of friends. They often got together on Saturday nights to play and watch sports. One weekend most of the members of the group couldn't attend. Instead of poker, Philip went over to his friend's house to play Trivial Pursuit. There were snacks and soda to munch on while they played. Philip had never played the game before, so his friend explained it to him. They played until late in the evening. Philip decided he wanted to get a copy of the game for himself. 


\section{Trait judgment question}

Statement: Philip is smart.

\section{References}

Albrecht, J. E., \& O’Brien, E. J. (1993). Updating a mental model: Maintaining both local and global coherence. Journal of Experimental Psychology. Learning, Memory, and Cognition, 19, 1061-1070.

Baumeister, R. F., Bratslavsky, E., Finkenauer, C., \& Vohs, K. D. (2001). Bad is stronger than good. Review of General Psychology, 5, 323-370.

Brewer, W. F., \& Lichtenstein, E. H. (1982). Stories are to entertain: A structural-affect theory of stories. Journal of Pragmatics, 6, 473486.

Campion, N., Martins, D., \& Wilhelm, A. (2009). Contradictions and predictions: Two sources of uncertainty that raise the cognitive interest of readers. Discourse Processes, 46, 341-368.

Doyle, A. C. (1890). The sign of the four. Retrieved from www.gutenberg.org/files/2097/.

Egidi, G., \& Gerrig, R. J. (2009). How valence affects language processing: Negativity bias and mood congruence in narrative comprehension. Memory \& Cognition, 37, 547-555.

Ferreira, F., \& Clifton, C. (1986). The independence of syntactic processing. Journal of Memory and Language, 25, 348-368.

Gernsbacher, M. A. (1990). Language comprehension as structure building. Hillsdale, NJ: Erlbaum.

Gernsbacher, M. A., Goldsmith, H. H., \& Robertson, R. R. W. (1992). Do readers mentally represent characters' emotional states? Cognition and Emotion, 6, 89-111.

Gernsbacher, M. A., Hallada, B. M., \& Robertson, R. R. W. (1998). How automatically do readers infer fictional characters' emotional states? Scientific Studies of Reading, 2, 271-300.

Gernsbacher, M. A., \& Robertson, R. R. W. (1993). Knowledge activation versus sentence mapping when representing fictional characters' emotional states. Language and Cognitive Processes, 7, 353-371.

Gerrig, R. J., \& Jacovina, M. E. (2009). Reader participation in the experience of narrative. In B. H. Ross (Ed.), The psychology of learning and motivation (Vol. 51, pp. 223-252). New York: Academic Press.

Guéraud, S., Harmon, M. E., \& Peracchi, K. A. (2005). Updating situation models: The memory-based contribution. Discourse Processes, 39, 243-263.

Gygax, P., Garnham, A., \& Oakhill, J. (2004). Inferring characters' emotional states: Can readers infer specific emotions? Language and Cognitive Processes, 19, 613-639.

Gygax, P., Oakhill, J., \& Garnham, A. (2003). The representation of characters' emotional responses: Do readers infer specific emotions? Cognition and Emotion, 17, 413-428.

Hakala, C. M., \& O’Brien, E. J. (1995). Strategies for resolving coherence breaks in reading. Discourse Processes, 20, 167-185.

Jacovina, M. E., \& Gerrig, R. J. (2010). How readers experience characters' decisions. Memory \& Cognition, 38, 753-761.

Jose, P. E., \& Brewer, W. F. (1984). Development of story liking: Character identification, suspense, and outcome resolution. Developmental Psychology, 20, 911-924.

Just, M. A., \& Carpenter, P. A. (1987). The psychology of reading and language comprehension. Boston: Allyn \& Bacon.

Levine, W. H., \& Klin, C. M. (2001). Tracking of spatial information in narratives. Memory \& Cognition, 29, 327-335.
Mandler, J. M. (1984). Stories, scripts, and scenes: Aspects of schema theory. Hillsdale, NJ: Erlbaum.

Morrow, D. G., Greenspan, S. L., \& Bower, S. L. (1987). Accessibility and situation models in narrative comprehension. Journal of Memory and Language, 26, 165-187.

O’Brien, E. J., Rizzella, M. L., Albrecht, J. E., \& Halleran, J. G. (1998). Updating a situation model: A memory-based text processing view. Journal of Experimental Psychology. Learning, Memory, and Cognition, 24, 1200-1210.

Peeters, G., \& Czapinski, J. (1990). Positive-negative asymmetry in evaluations: The distinction between affective and informational negativity effects. European Review of Social Psychology, 1, $33-60$.

Peracchi, K. A., \& O’Brien, E. J. (2004). Character profiles and the activation of predictive inferences. Memory \& Cognition, 32, $1044-1052$.

Rapp, D. N. (2008). How do readers handle incorrect information during reading? Memory \& Cognition, 36, 688-701.

Rapp, D. N., \& Gerrig, R. J. (2002). Readers' reality-driven and plotdriven analyses in narrative comprehension. Memory \& Cognition, 30, 779-788.

Rapp, D. N., \& Gerrig, R. J. (2006). Predilections for narrative outcomes: The impact of story contexts and reader preferences. Journal of Memory and Language, 54, 54-67.

Rapp, D. N., Gerrig, R. J., \& Prentice, D. A. (2001). Readers' traitbased models of characters in narrative comprehension. Journal of Memory and Language, 45, 737-750.

Rapp, D. N., \& Kendeou, P. (2007). Revising what readers know: Updating text representations during narrative comprehension. Memory \& Cognition, 35, 2019-2032.

Rapp, D. N., \& Kendeou, P. (2009). Noticing and revising discrepancies as texts unfold. Discourse Processes, 46, 1-24.

Rapp, D. N., \& Mensink, M. C. (in press). Focusing effects from online and offline reading tasks. To appear in M. T. McCrudden, J. P. Magliano, \& G. Schraw (Eds.), Text relevance and learning from text.

Sparks, J. R., \& Rapp, D. N. (2011). Readers' reliance on source credibility in the service of inference generation. Journal of Experimental Psychology. Learning, Memory, and Cognition, 37, 230-247.

Trueswell, J. C., Tanenhaus, M. K., \& Garnsey, S. (1994). Semantic influences on parsing: Use of thematic role information in syntactic ambiguity resolution. Journal of Memory and Language, 33, 285-318.

Uleman, J. S., Hon, A., Roman, R. J., \& Moskowitz, G. B. (1996). On-line evidence for spontaneous trait inferences at encoding. Personality and Social Psychology Bulletin, 22, 377-394.

Zwaan, R. A. (1996). Processing narrative time shifts. Journal of Experimental Psychology. Learning, Memory, and Cognition, 22, 1196-1207.

Zwaan, R. A., Langston, M. C., \& Graesser, A. C. (1995). The construction of situation models in narrative comprehension: An event-indexing model. Psychological Science, 6, 292-297.

Zwaan, R. A., Magliano, J. P., \& Graesser, A. C. (1995). Dimensions of situation model construction in narrative comprehension. Journal of Experimental Psychology. Learning, Memory, and Cognition, 21, 386-397.

Zwaan, R. A., \& Radvansky, G. A. (1998). Situation models in language comprehension and memory. Psychological Bulletin, $123,162-185$.

Zwaan, R. A., \& Rapp, D. N. (2006). Discourse comprehension. In M. A. Gernsbacher \& M. J. Traxler (Eds.), Handbook of psycholinguistics (pp. 725-764). San Diego: Elsevier. 